\title{
Desdobramentos de uma arquitetura do Data Center ${ }^{1}$
}

\author{
Michel Zisman Zalis \\ Arquiteto pelo Departamento de Arquitetura e Urbanismo da PUC-Rio. \\ Contato: michelzzalis@gmail.com
}

\section{RESUMO}

Este trabalho investiga os impactos ambientais, sociais, urbanos e paisagísticos decorrentes da infraestrutura da internet, a partir do estudo de caso da grande ressonância arquitetônica desse sistema: o Data Center, um tipo de edifício em ampla multiplicação que evidencia a fisicalidade de um sistema que se apresenta como nebuloso, onipotente e ubíquo. A partir de exemplos elegidos, instiga-se a desenvolver análises dessas arquiteturas hipertecnológicas, discutindo seus aspectos formais e sócio-ambientais. A centralidade vital da infraestrutura da internet em uma sociedade cada vez mais conectada reverbera desafios existentes, mas cada vez mais complexos, como processos de urbanização, acesso desigual à comunicação e alto impacto ambiental, integrando o debate dos possíveis caminhos do campo da arquitetura nos desdobramentos da era digital.

Palavras-chave: Data Center; Infraestrutura; Arquitetura da Internet; Fisicalidade da Internet.

\section{Data Center Architecture Unfolding}

\section{ABSTRACT}

This work investigates the environmental, social, urban, and landscape impacts resulting from the internet infrastructure, focusing on the case study of the great architectural resonance of this system: The Data Center - a type of building in wide multiplication that highlights the physicality of a system that presents itself as cloudy, omnipotent, and ubiquitous. Based on selected examples, it analyzes these hyper-technological architectures, discussing their formal and socio-environmental aspects. The vital centrality of internet infrastructure in an increasingly connected society reverberates existing but increasingly complex challenges, such as urbanization processes, unequal access to communication, and high environmental impact, integrating the debate on possible paths in the field of architecture in the developments of the digital age.

Keywords: Data Center; Infrastructure; Internet Architecture; Internet’s physicality. 


\section{Introduçáo}

"Eu não tenho ideia do que é a Internet" (METREVELLI, 2011). Foi o que disse Hayastan Shakarian, após ter sido presa por cortar um cabo enquanto procurava cobre para vender ao ferro velho. A georgiana de 75 anos foi acusada pelo rompimento do cabo que alimenta a infraestrutura da Internet da Armênia, deixando milhões de pessoas off-line. Por não ter acesso direto ao mar, os cabos de fibra ótica submarinos que conectam a Armênia aos grandes centros econômicos e culturais são recepcionados na zona industrial de Poti, no litoral da Georgia. A partir daí, os cabos de fibra ótica, enterrados sob a paisagem caucasiana, chegam até ramais das operadoras de telefonia armênias que distribuem os dados de Internet em todo o país.

É pouco provável que Hayastan, até o incidente ocorrido em 2011, não tivesse se conectado à Internet, seja através de redes sociais, compras on-line ou até serviços públicos. Talvez não teria facilidade de explicar o que é a Internet, mas provavelmente reconheceria sua utilidade por meio de celulares ou computadores. Essa "ideia”, portanto, assim colocada por ela, não estaria relacionada de fato ao desconhecimento da existência da Internet, mas sim ao encobrimento da materialidade de sua infraestrutura. Além de evidenciar sua fisicalidade, Hayastan, com seu fortuito poder, revela a fragilidade dessa rede global de telecomunicações.

Sublinhada por suas terminologias como nuvem, wifi e bluetooth, a Internet é apresentada como uma entidade “(...) onipresente, efêmera, em todo lugar e em nenhum lugar" (YOUNG, 2019, p. 59, tradução do autor), comandada porempresas da chamada GAFAM, ${ }^{2}$ que, através de seus serviços de armazenamento de dados, têm atribuições que tangem a onipotência e onipresença. Essa percepção abastece um sentido interpretativo como algo que percorre a ordem do nebuloso, ofuscando a fisicalidade de sua infraestrutura de funcionamento, como coloca Guilherme Wisnik:

Metaforicamente, ela (a nuvem) nos aparece como um meio informe, transparente e cada vez mais acessível, que naturaliza, no entanto, as redes de poder a ela associadas, ocultando toda a gigantesca gama de infraestrutura física que existe para realizá-la e mantê-la em funcionamento 24 horas por dia segundo padrões seguros, com baterias e geradores suplementares. (WISNIK, 2018, p. 101)
Ou seja, a nuvem se posiciona como uma ferramenta de abstração do funcionamento da Internet. Por um lado, acredita-se na proximidade com a tecnologia devido a sua autonomia, sua ubiquidade e a quase onipotência da interface, por outro lado, há um distanciamento real entre o usuário e a infraestrutura. O incidente da georgiana revelou, portanto, a falaciosa percepção de que a Internet funciona através de redes metafísicas que interconectam pessoas, empresas e governos ao redor do globo através de uma nuvem diluída no éter, derivando pelo ar. $\mathrm{O}$ fio fissurado, em realidade, participa de uma infraestrutura pesada de escala planetária transnacional (Fig. 1), composta por cabos, antenas, modens, prédios, leis e protocolos, esfomeada por recursos minerais e sedenta por água. Toda essa infraestrutura precisa estar sob um regime de alta segurança, no qual sistemas de vigilância se tornam um imperativo de sua existência.

O ocultamento desse sistema pode ser analisado a partir de sua performance legislada por uma velocidade imperceptível ao olho humano, como também por sua política de aparência que resguarda, esconde e defende. O pretexto da segurança dos dados se embaralha com a opacidade das dinâmicas de transição e domínio, que amplia a nebulosidade dos funcionamentos internos, se mantendo de forma abstrata para a maioria dos usuários.

A revelação da fisicalidade da Internet foi um alerta para meu Trabalho de Conclusão de Curso no ano de 2020, no qual busquei investigar as manifestações físicas da Internet e as possíveis interações entre sua infraestrutura e o campo da arquitetura. A pesquisa se utiliza da ambígua paridade conceitual entre aparência e performance postulada por Reyner Banham na comparação entre a bota de esqui Salo-

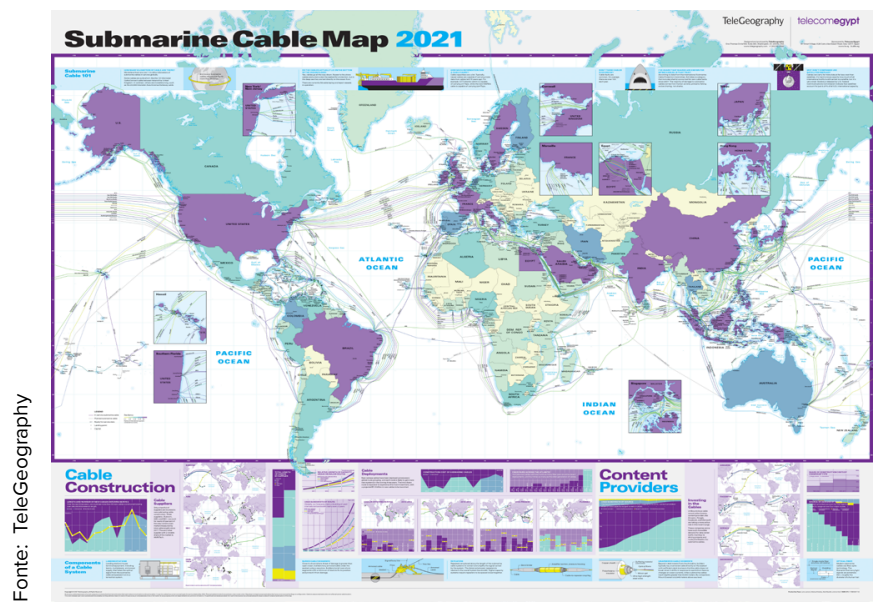

Figura 1. Mapa de Cabos de fibra ótica Submarinos desenvolvido pela TeleGeography, 2019 
mon Downhill e a bicicleta Moulton AM7, no que viria a ser a introdução de seu próximo livro sobre a arquitetura High Tech dos anos 1970 . $^{3}$ A partir de leituras como essa, pode-se interpretar que, para Banham, projetos que se aventuram na aproximação com a tecnologia estão sujeitos a tal ambiguidade, haja vista que a aparência de um edifício é confrontada pela capacidade do olhar humano de compreender sua performatividade tecnológica. $\mathrm{O}$ processo arquitetônico de revelação coincide, portanto, na possibilidade de aliar a performance tecnológica com a aparência do edifício.

Desnudar, revelar, exibir e evidenciar são operações introdutórias no percurso investigativo de interpretação e análise de um sistema disposto em rede, descentralizado e quase invisível das errâncias do dia a dia. De todo modo, a presente pesquisa se dedicou a investigar pontos de interseção entre arquitetura, cidade e Internet na busca por possíveis caminhos da disciplina no debate contemporâneo sobre os desdobramentos da era digital.

\section{Desdobramentos de uma arquitetura do Data Center}

É só dar o sinal que, como um bumerangue, ondas de rádio são transmitidas de seu celular para seu roteador do wifi. Então, transformadas em fótons codificados, atravessam o cabo de rede da sua casa, que é ligado ao cabo de rede do prédio, que, por sua vez, se junta a uma grande estrutura de cabos enterrados debaixo das cidades para serem recepcionados em um ponto de intercâmbio de rede local. Lá, essa grande estrutura se aglutina a um cabo de maior capacidade - os chamados backbones - para então ser direcionado às estações de cabos submarinos, onde se concentram em cabos que atravessam os oceanos. Chegando à estação de recepção do país que lhe é direcionado, a informação percorre cabos e pontos de intercâmbio para chegar até algum Data Center, ${ }^{4}$ onde captura a informação e volta, possivelmente pelo mesmo caminho.

O Data Center é uma arquitetura em ampla expansão. Seu crescimento acompanha o exponencial crescimento de dados gerados e difundidos (Fig. 2), suscitando uma arquitetura baseada em oferta e demanda. Um relatório da International Data Company (REINSEL; GANTZ; RYDNIN, 2018, p. 6) estimou que, em 2018, haviam 33 Zetabytes (ZB) na chamada Datasphere - toda a esfera sistêmica dos dados - e previu que em 2025 chegará a 175ZB. Entretanto, a velocidade de acúmulo exponencial do software não é acompanhada pelos avanços do hardware, restando apenas a produção massiva de Data Centers para ser o armário utilitário para guardar toda a produção massiva de dados previstos nos próximos anos.

O Data Center oferece uma nova possibilidade para a arquitetura. Se a tradição humanista nos direcionou para uma construção dedicada à centralidade humana, a arquitetura de arquivamento de dados coloca em seu centro a máquina. Na mesma ótica da discussão sobre espaços serventes e servidos proposta por Louis Kahn (2010, p. 78), a paisagem do empilhamento de servidores reverbera sua etimologia como uma arquitetura servidora - mantém-se na periferia do núcleo na hierarquia espacial e concentra uma tecnologia disposta a servir à razão do projeto. Ampliando a escala de tal conceituação, rasgando os limites do envelope, o Data Center possui como função o armazenamento e processamento de dados de 4,57 bilhões de pessoas no mundo, ${ }^{5}$ que utilizam interfaces autônomas, abstraindo todo processo que lhes serve por trás. Esse movimento de olhar para arquitetura que serve, e não para a arquitetura que é servida, é um processo de revelação daquilo que não é usualmente visível (BANHAM, 1984, p. 12).

Data Centers não são prédios de fácil reconhecimento a partir de sua aparência. Por exemplo, um Data Center da empresa Equinix (Fig. 3) se encontra na esquina da Rua Voluntários da Pátria com a Rua Martins Ferreira, no bairro de Botafogo, Rio de Janeiro. O edifício de esquina, revestido de pedras amarronzadas, é incorporado pelo contexto de altos prédios de escritórios e moradias na rua principal do bairro. Contudo, certos aspectos sugerem a presença de um Data Center. A tubulação exposta anexada à fachada indica uma adaptação da estrutura predial para alimentar um programa sedento por refrigeração. Tal fato pode ser também reparado por fotos de satélite, que mostram a massiva quantidade de

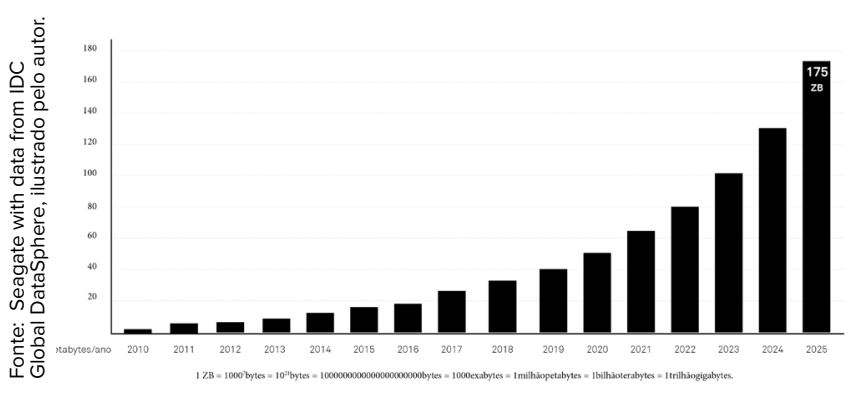

Figura 2. Gráfico da previsão de crescimento da geração de dados até $2025,2018$. 
máquinas de ar-condicionado no terraço do edifício. Seu térreo é circundado por uma grade preta e câmeras suspensas sob a marquise, que protege da chuva e do sol a pequena entrada de portas envidraçadas. A entrada é permitida por dois seguranças que guardam, atrás de um vidro à prova de balas, a recepção com o logo da Equinix, um signo que representa uma das maiores empresas de Data Center do mundo.

Um Data Center é, predominantemente, uma infraestrutura envelopada contendo gabinetes e computadores de alta tecnologia em um ambiente climatizado, circundada por um sistema de alta segurança. No caso do Equinix Botafogo, requalificou-se um prédio de escritórios para servir como essa estrutura de arquivamento tecnológica.

Equinix é uma empresa de Data Center de colocação, ou seja, que oferece hospedagem de servidores para clientes corporativos. As empresas podem adquirir espaço nos servidores ou até comprar uma quantidade de metragem quadrada privada para alocar sua própria biblioteca de dados. Dependendo da escala, esse tipo de edifício pode se instalar em centros urbanos, mais perto dos usuários e dos pontos de troca de tráfego. São lugares de interconexão de redes compartilhadas entre os provedores de Internet (DIGUET e LOPEZ, 2019, p. 18) - no caso do Brasil, as grandes empresas de telecomunicação: Oi, Tim, Claro e Algar.

A requalificação é facilitada em edifícios que já abrigaram tecnologias passadas, como pontos de telefonia, pois já oferecem um espaço técnico generoso, um piso resistente para aguentar a carga das máquinas, antenas e grandes espaços abertos (DIGUET e LOPEZ, p. 32). Esse é o caso do edifício 60 Hudson Street (Fig. 4), em Nova Iorque, construído pelo arquiteto Ralph Walker para hospedar a empresa de telégrafo Western Union. Hoje, o edifício acomoda diversas empresas de tecnologia de informação. A construção Art Déco de 1930 é um sintoma da cultura de congestão citada por Rem Koolhaas em seu manifesto retroativo sobre Nova Iorque. A "conquista de cada quadra por uma estrutura única" (KOOLHAAS, 2008, p. 151) se apresenta como um grande monolito lapidado sob custódia da Lei de Zoneamento de 1916 - o famigerado "bolo de noiva" que oferece pequenos terraços. Nestes, são percebidas as condensadoras de ar-condicionado distribuídas verticalmente nos espaços que lhe cabem, transformando esse edifício em uma grande máquina limitada pela retícula nova-iorquina. É um prédio feito para máquinas, diferentemente de seu entorno, onde a corrida fálica

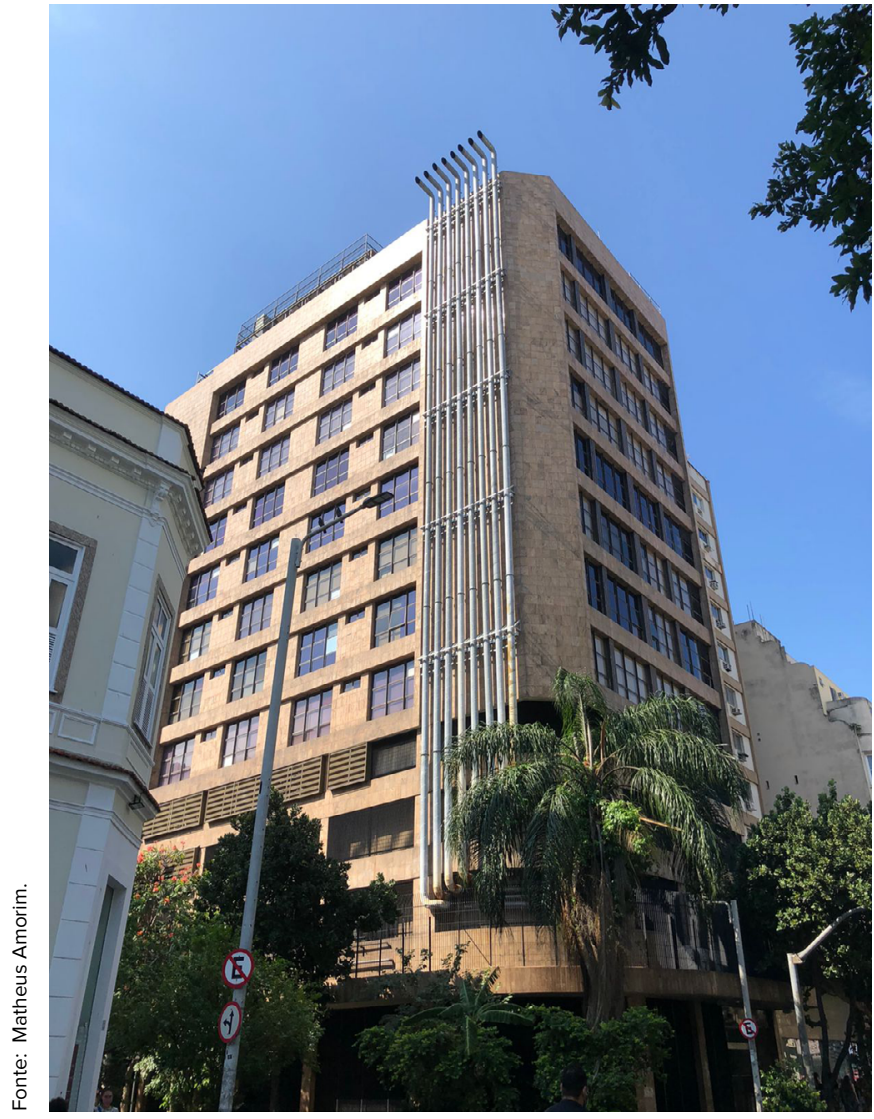

Figura 3. Data Center da Equinix no Bairro de Botafogo, Rio de Janeiro, 2020.

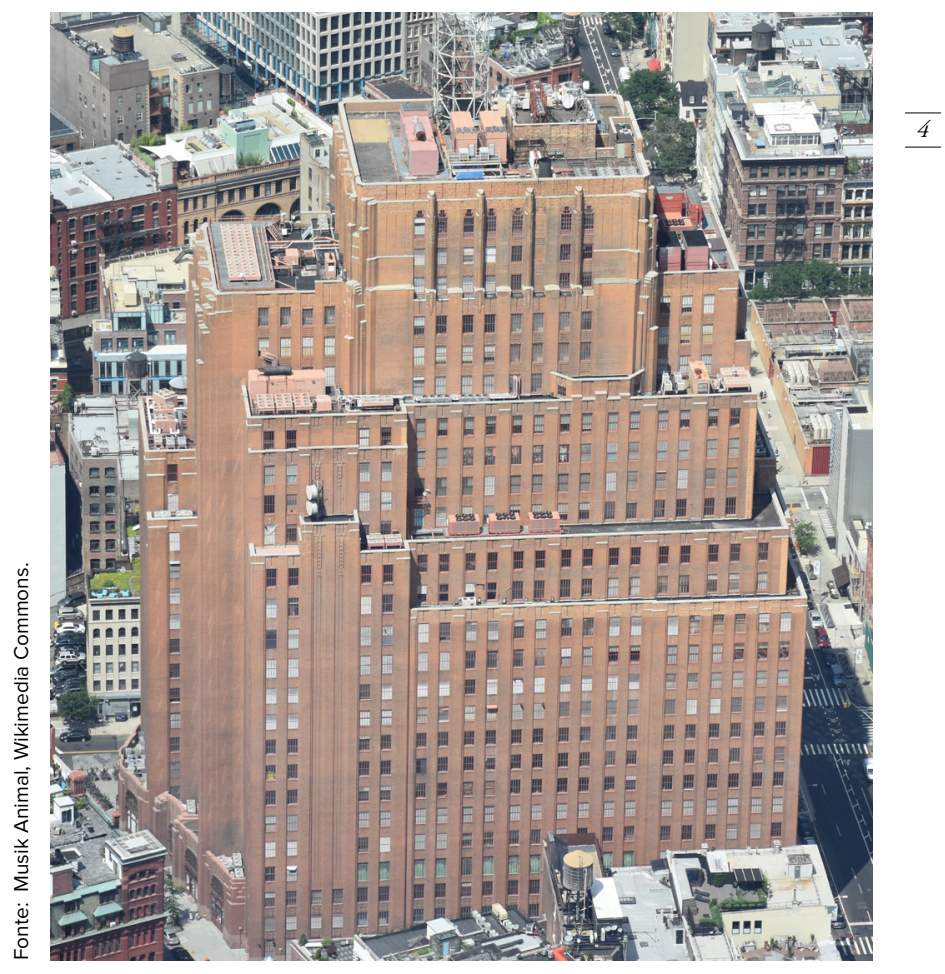

Figura 4. 6o Hudson Street, Nova Iorque, 2015. 
para o céu agrupa empresas e habitações que mantém a congestão e vitalidade urbana de Nova Iorque.

Se o elevador é o facilitador da tecnologia do fantástico (KOOLHAAS, 2008), que se manifesta na sobreposição de andares desconexos, são os prismas verticais onde passam os cabos e tubos que permitem o funcionamento da tecnologia digital. Assim, cria-se uma relação entre a retícula racionalista de Manhattan e a retícula racionalista do Data Center. Enquanto programas autônomos e desconexos se empilham na simultaneidade dinâmica e heterogênea do arranha céu, servidores são empilhados até o limite industrial de um gabinete - sua altura de fabricação (cerca de 2 metros) - que acumula, a cada andar, variáveis subjetividades, memórias, planilhas e documentos. Nesse caso, a lobotomia, como Koolhaas coloca, é a mesma. Se o indecifrável 60 Hudson Street "poupa ao mundo externo as agonias das mudanças contínuas que grassam" (KOOLHAAS, 2008, p. 126), em seu inte-

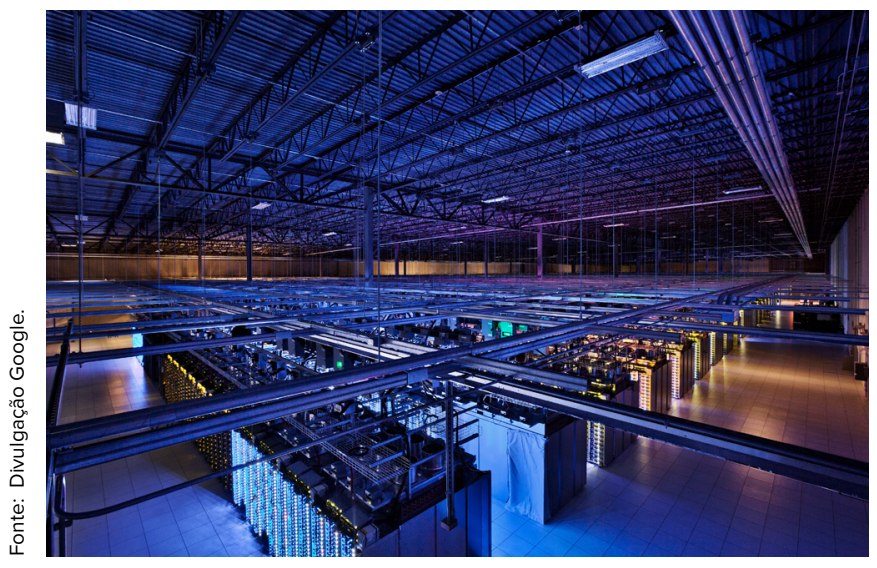

Figura 5. Data Center Google, Iowa, EUA.

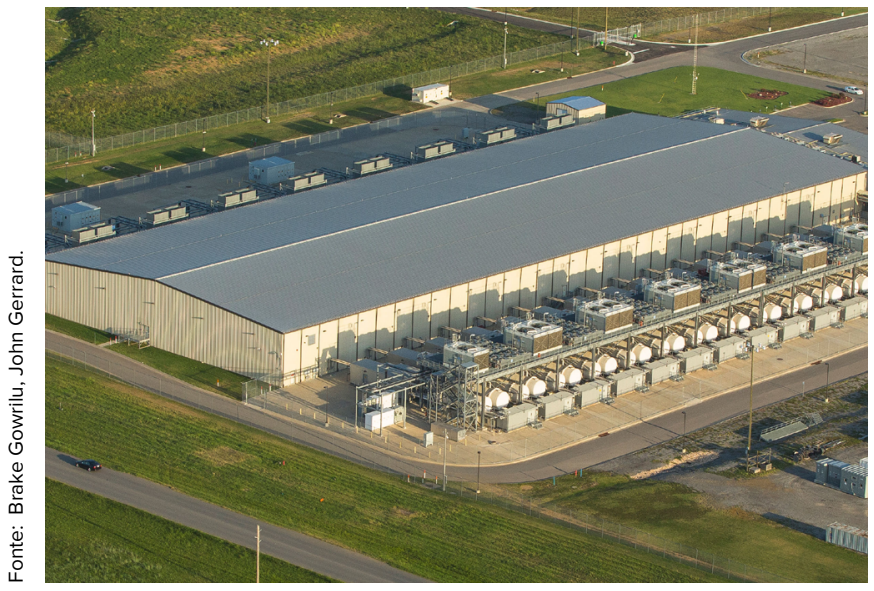

Figura 6. Registro do Data Center Google em Oklahoma para a série Farm, 2015. rior, a aparência externa do monolito eletrônico não oferece nenhuma pista para o seu funcionamento interior.

Dessa forma, é importante criar estratégias de identificação dessa tipologia. Enquanto um Data Center urbano está suscetível a limitações - tal como a quantidade de servidores disponibilizados levando em conta a impossibilidade de expansão, a quantidade de equipamentos de resfriamento necessária para mantê-los e a quantidade de energia consumida que uma cidade pode suportar - "instalações gigantescas estão aparecendo sobre belas paisagens" (KOOLHAAS, 2019, p. 64, tradução do autor). Em áreas rurais, onde espaço disponível e a quantidade de energia gerada são abundantes, a capacidade de ampliação e multiplicação se potencializa - é onde se desenvolve uma paisagem decorrente do crescimento da infraestrutura da Internet, pela multiplicação de edifícios inexpressivos que podemos confundir com tipos familiares, como uma fábrica ou um shopping center do subúrbio estadunidense. Sobretudo, um olhar atento perceberia as nuances formais desses "galpões não decorados"6 que incorporam sua performance tecnológica.

O Data Center não permite ventilação natural, são grandes envelopes fechados sem janelas. A temperatura deve ser mantida na faixa dos 22 graus Celsius para equilibrar o vento quente de exalação das máquinas e manter a umidade na faixa dos $0,006 \mathrm{~g} / \mathrm{kg}$, evitando o aquecimento das máquinas ou condensação de água. Sobre um piso aberto, uma paisagem de malha regular horizontal é habitada por colunas e colunas de gabinetes de servidores, que armazenam os dados que compõem a história coletiva digital (Fig. 5). Não há demanda para luz natural, restando apenas o piscar das luzes dos servidores, como vagalumes que brilham ao receber um sinal de interação, que se intercalam com as luzes frias que iluminam o solitário trabalho dos técnicos de servidores (YOUNG, 2019, p. 8). ${ }^{7}$

Todo esse aparato tecnológico requer grandes infraestruturas de resfriamento. Ao visualizar as fotografias de John Gerrard em sua série Farm (Fig. 6), é possível observar o contraste formal entre a infraestrutura acoplada e a arquitetura em si como uma hiperbolização da serventia espacial. $O$ interessante é o contraste da tecnologia exposta nas fachadas do edifício, digna do paradigma mecânico, que serve aos servidores no interior do edifício, pertencentes ao paradigma eletrônico (EISENMAN, [1992], 2013) e legislados por outros protocolos: dos bytes e da hipervelocidade. É justamente a quantidade anormal de uma infraestrutura exposta que se

Revista online do Departamento de Arquitetura e Urbanismo da Pontifícia Universidade Católica do Rio de Janeiro - PUC-Rio, Brasil Ano 8 - No으 9 - ISSN 2446-7340 
tornou um signo para identificação de um Data Center, tal como a cruz identifica a igreja.

\section{Impactos Energéticos}

Esse cenário de um maquinário pesado representa, também, uma arquitetura agressiva ao meio ambiente. Em um relatório sobre os impactos energéticos e espaciais dos Data Centers, as francesas Celile Diguet e Fanny Lopez avaliam que os principais problemas de energia e de recursos se resumem principalmente a: fome de energia das infraestruturas de resfriamento; redundância necessária para manter um backup no caso de qualquer colapso; excesso e falta de efetividade dos servidores; e o longo ciclo de vida de metais raros e sílica usados para os equipamentos eletrônicos e digitais em comparação a sua rápida obsolescência (DIGUET e LOPEZ, 2019).

Como já mencionado, o resfriamento das salas é vital para a funcionalidade dos servidores. Cada servidor funciona como um computador, o qual necessita de ventiladores internos para liberar o ar quente consequente da atividade. Ar, este, que é liberado pela sua parte traseira. Uma fileira de gabinetes com dezenas de servidores libera uma quantidade significativa de ar quente, gerando ilhas de calor intercaladas. Dessa forma, se utiliza um sistema de resfriamento a partir de um piso elevado que faz o ar frio, mais denso, expelir o ar quente para os exaustores.

Em um artigo notável sobre a poluição gerada pelos centros de dados, o jornalista estadunidense James Glanz (2012) sinaliza a quantidade exagerada de energia consumida, na qual apenas um prédio pode representar a quantidade de energia de uma cidade média. Segundo Glanz, em 2010, foram utilizados 78 bilhões de $\mathrm{KW} / \mathrm{h}$, cerca de $2 \%$ da energia utilizada em todo os EUA naquele ano.

$\mathrm{O}$ alto gasto energético se refere também à responsabilidade de manter os servidores sem qualquer interrupção. Não deve haver espaço para qualquer ameaça, como possíveis quedas de energia, de tal forma que existem salas com grandes motores de combustão a óleo diesel (Fig. 7), potente poluente do ar, à espera de quaisquer problemas para serem acionados e autossustentar o Data Center por alguns dias. Porém, como os geradores demoram alguns minutos para começar a operar, pilhas e pilhas de baterias automaticamente despertariam para manter os servidores ligados durante esse hiato em uma potencial catástrofe.
Uma outra medida para evitar o colapso dos dados é a redundância, pela qual os dados são replicados duas ou três vezes em mais de um Data Center, possivelmente em diferentes países. O que nos leva a crer que existem prédios de gastos energéticos exorbitantes, danosos ao meio ambiente, com apenas a função de dar apoio emergencial. A lógica da infraestrutura da nuvem é enraizada no excesso, redundância e contingenciamento, governados pelo preparo para o pior dos cenários. Basicamente, uma arquitetura na iminência de uma emergência.

De acordo com a ONG Greenpeace (2017), se o sistema da Internet fosse um país, que agrupa, além dos Data Centers, a produção de eletrônicos, a utilização de interfaces e toda a infraestrutura de funcionamento estaria em terceiro lugar no ranking de consumo energético mundial, atrás apenas da China e dos EUA. O sistema cresce exponencialmente e é potencializado pelo processo de digitalização que cada vez mais se faz de todas as instâncias da vida humana. Seu excesso de redundância, o alto gasto energético e a obsolescência programada transformam o Data Center em uma "tipologia construtiva quintessencial da era da informação" (FARD, 2018, p. 69, tradução do autor).

A empresa de tecnologia Cisco (2018) prevê um crescimento exorbitante da utilização das tecnologias da informação até 2023, no qual equipamentos ligados à Internet chegarão à marca de 15 bilhões. Uma previsão feita por Anders S. G. Andrae e Tomas Edler (2015, p. 137) prevê que, em 2030, o pior cenário incluiria $51 \%$ da energia mundial sendo consumida somente por equipamentos pertencentes à Internet das coisas.

É uma geração de informação que pode não possuir qualquer importância e nunca mais ser revisitada, porém é guar-

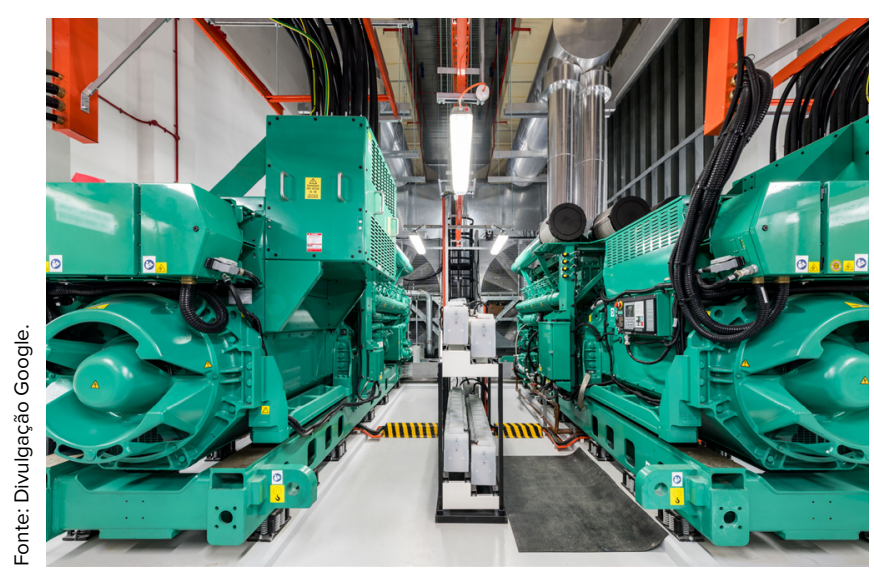

Figura 7. Geradores a diesel, Data Center Google, Singapura. 
dada em edifícios sob um regime de alta segurança, dependentes do consumo massivo de recursos energéticos. Anders e Tomas (2015, p. 133) mencionam também que até 2030 os Data Centers podem ser responsáveis por $13 \%$ do consumo energético do planeta.

Como já indicado, a relação direta entre o acúmulo crônico de dados e a reprodução em massa dos Data Centers propõe uma condição contemporânea dominada pela tecnologia de informação que prevê cada vez mais o desgaste do meio ambiente. Nesse sentido, os processos de modernização se apresentam na condição de hipervalorização e preservação do mundo digital, escorados por montes de lixo eletrônico (Fig. 8) distribuídos pela periferia do planeta, que evidenciam o resultado de uma obsolescência programada amparada pelo avanço tecnológico. O Data Center se encontra como o guardião dessa digitalização, com a responsabilidade de defender, manter e assegurar que aquilo guardado nunca seja esquecido.

\section{Aparência performática de segurança}

Sua importância e responsabilidade de ser guardião das memórias digitais de indivíduos, empresas e governos ao redor do globo exigem a necessidade de um complexo sistema de segurança, como bolhas dentro de bolhas. Senhas, cartões, reconhecimento facial, sensores de movimento e muitas câmeras de vigilância mantém a integridade do sistema de dados. Os Data Centers mais seguros possuem até uma balança na porta de acesso para garantir o mesmo peso da pessoa que entrou e que saiu. Como há espaço para desconfiança, cria-se um teatro publicitário da vigilância, pois todos os usuários devem confiar na empresa para depositar suas vidas em bytes. Não é suficiente ser seguro, há de parecer seguro.

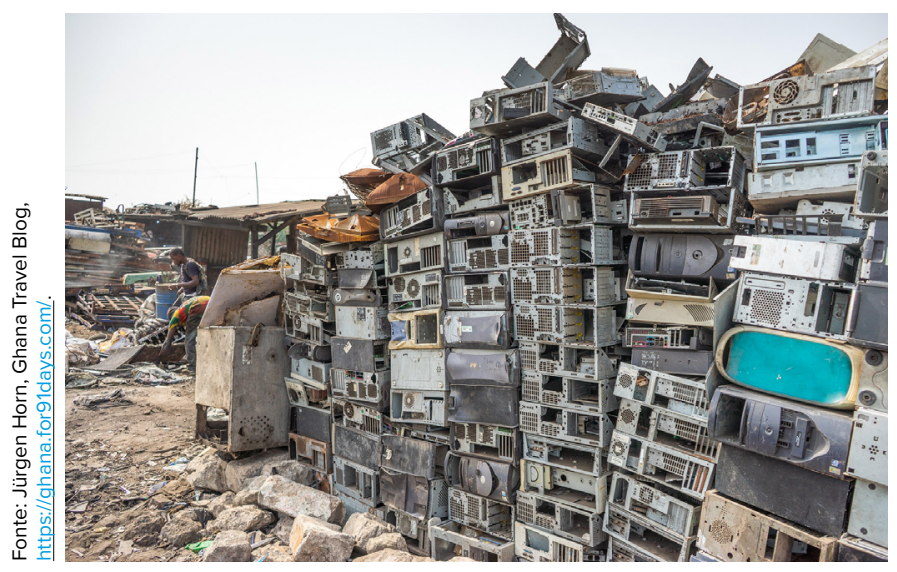

Figura 8. Lixão eletrônico, Agbogbloshie, Acra, Gana, 2019.
Por esse motivo, a segurança performática do Data Center pode, também, recorrer a uma aparência performática de segurança. A necessidade de ser um lugar seguro levou certas empresas a buscarem arquiteturas pré-existentes que são aparentemente seguras, como afirma Stephen Graham: Além de sua aparência protetiva, empresas utilizam a imagem atraente do contraste entre o vernacular e o tecnológico para desenvolver um conteúdo publicitário, se aproveitando de um cenário irreverente para atrair empresas e usuários.

(...) longe dos principais centros metropolitanos, silos de mísseis balísticos, minas de sal fechadas e fortes antiaéreos estão sendo transformados em centros de armazenamento e backup de dados. Eles oferecem instalações de arquivamento de dados ultra seguras, usando o regolito acumulado da arquitetura militar abandonada desde o final do século XX. (GRAHAM, 2012, p. 20, tradução do autor)

Esse é o caso da Bahnhof AB (Fig. 9), na Suécia, que opera 30 metros abaixo do chão, em um antigo bunker originalmente usado para proteger civis de possíveis ataques nucleares durante a Guerra Fria. Projeto do escritório sueco Albert France-Lanord Architects, o Data Center, inaugurado em 2008, "oferece vistas particularmente dramáticas, completas com motores a diesel de submarinos alemães para backup e paredes de pedra brilhantes e sem janelas, protegendo servidores que piscam, empilhados no subsolo" (HOLT e VONDERAU, 2015, p. 72, tradução do autor). As referências aos filmes de ficção científica ou os antigos James Bond - um briefing do cliente (ALGER, 2013, p. 6o) - remetem a uma intencionalidade de criar uma aparência baseada na estética futurista, enraizada em filmes como Star Trek e 2001: Uma odisseia no espaço, nos livros de William Gibson como Neuromancer, ou nos programas de TV como Os Jetsons, que guiam uma ideia coletiva dos impactos estéticos da tecnologia, influenciando a imagem desses artefatos. Entre os panos de vidro e os revestimentos metálicos, um paisagismo artificial com cachoeiras e máquinas de fazer fumaça transformam esse bunker de dados em uma miscelânea de nostalgia militar, tecnologia avançada e cenografia publicitária.

Já o Swiss Fort Knox, autoproclamado como o Data Center mais seguro da Europa, se localiza dentro dos Alpes Suíços. As duas sedes, a 10km de distância, operam em dois bunkers desativados da Guerra Fria. Além de ser dentro de uma montanha, oferecendo risco mínimo à infraestrutura, a empre-

Revista online do Departamento de Arquitetura e Urbanismo da Pontifícia Universidade Católica do Rio de Janeiro - PUC-Rio, Brasil Ano 8 - No 9 - ISSN 2446-7340 


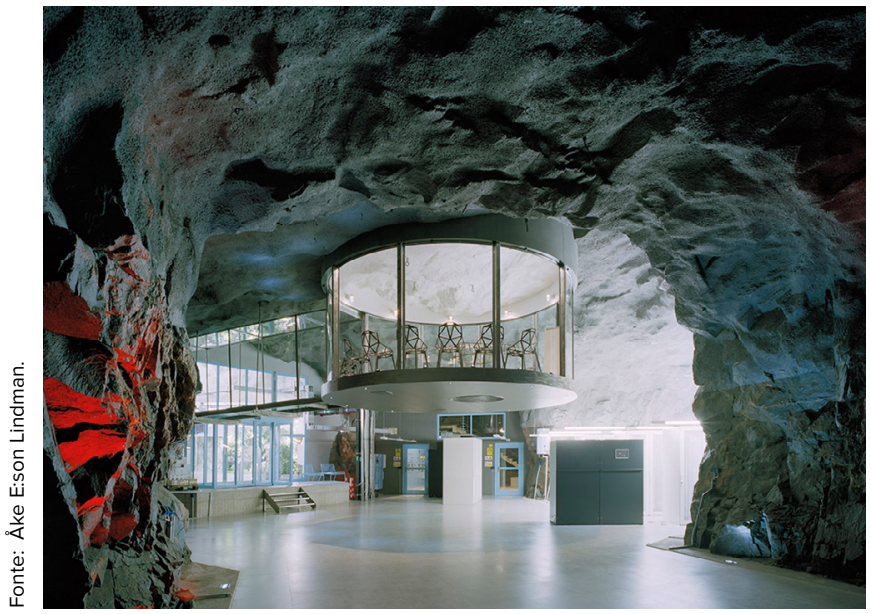

Figura 9. Data Center Banhhof AB, Suécia.

sa oferece um sistema de vigilância de alarmes, seguranças treinados, câmeras, controle de biometria, salas privadas de servidores e diversos outros sistemas para manter tranquilos aqueles que lá arquivam seus dados. Além disso, inclui um hotel para convidados conhecerem a instalação e acesso direto a um aeroporto internacional. Seu sistema de resfriamento é também exclusivo, por meio da extração de águas glaciais em um lago subterrâneo profundo.

Assim como esse, existem muitos outros, como o The Bunker, na Inglaterra, o Cavern Technologies, nos Estados Unidos, o Data Bunker, no Canadá, ou o CyberBunker, na Alemanha. É notável que a publicidade da segurança começa no próprio nome, sinalizando o lugar pelo seu programa de origem em um contexto bélico, antes da requalificação.

De certo modo, ver as fotos dos centros de dados, publicadas pela própria empresa, parece revelar uma arquitetura que está normalmente por trás dos panos, como uma possível política de transparência. Entretanto, como afirmam Jennifer Holt e Patrick Vonderau (2015, p. 74, tradução do autor), "precisamos reconhecer que muitas das operações, padrões e dispositivos que estamos tentando descrever ao analisar a infraestrutura digital permanecerá oculta, trancada ou, em termos de engenharia, uma 'caixa preta'”. Seu próprio sistema de segurança e os locais escolhidos, na verdade, revelam que o Data Center é um lugar a ser escondido.

O caso do Edifício 33 Thomas Street, em Nova Iorque, pode contribuir para o debate sobre Data Center e segurança. Projetado em 1974 pelo arquiteto estadunidense John Carl Warnecke, o arranha-céu não possui nenhuma janela, apenas orifícios para ventilação no $10^{\circ}$ e $29^{\circ}$ andar. Um grande monolito revestido de granito sueco, construído para ser a central de telefonia da AT\&T, remete à imagem de um abrigo vertical para suportar um ataque nuclear em um mundo imerso na Guerra Fria. Porém, uma investigação (GALLAGER e MOLTKE, 2016) feita pelo canal de jornalismo The Intercept a partir dos documentos vazados por Edward Snowden, ${ }^{9} \mathrm{em}$ 2013, revelou que a aparência performática de segurança pode ser explicada pela relação obscura entre a Agência de Segurança Nacional dos Estados Unidos (NSA) e a AT\&T.

Com o codinome TITANPOINTE, os documentos revelados levam a crer que o Edifício 33 Thomas St. (Fig. 10) é um local de vigilância da NSA, onde seriam feitas interceptações de ligação, processamentos e arquivamentos de dados obtidos com grampeamento da Organização das Nações Unidas, Fundo Monetário Internacional e Banco Mundial em diversos países. Os fatos de o arquiteto John Carl Warnecke ter projetado diversos edifícios institucionais para o governo e ter construído outros prédios para AT\&T demonstram uma possível relação entre a empresa de telecomunicação e a NSA.

A descoberta de outros Data Centers da NSA (GALLAGER e MOLTKE, 2018) com uma semelhante aparência performática de segurança são documentos reais dos aspectos obscuros da política de transparência de dados e, principalmente, das potencialidades governamentais de vigilância e da falta de privacidade dos cidadãos. As revelações de Snowden sobre os programas de vigilância global feita pela NSA despertaram um maior foco sobre como os dados e as informações privadas são gerenciados e, principalmente, as formas de armazenamento e fluência da Internet. É possível afirmar, portanto, que o Data Center é uma tipologia arquitetônica estrutural para a manutenção de um modelo de sociedade na qual a vigilância desempenha papel primordial. Dessa forma, a revelação dos lugares em que estão tais Data Centers e toda sua infraestrutura global representam uma luta política pela transparência dos dados e, sobretudo, das vicissitudes de um sistema, que permanece oculto e distante de seus usuários.

\section{Considerações Finais}

A conceituação política por trás dos aspectos transcendentais da Internet deve mover a disciplina da arquitetura a buscar uma possível resistência debruçada na materialidade visível, sensível e real. A revelação e conscientização do poder dessa infraestrutura não deve depender de incidentes repentinos como de Hayastan Shakarian, mas da contínua investigação

Revista online do Departamento de Arquitetura e Urbanismo da Pontifícia Universidade Católica do Rio de Janeiro - PUC-Rio, Brasil Ano 8 - No으 9 - ISSN 2446-7340 


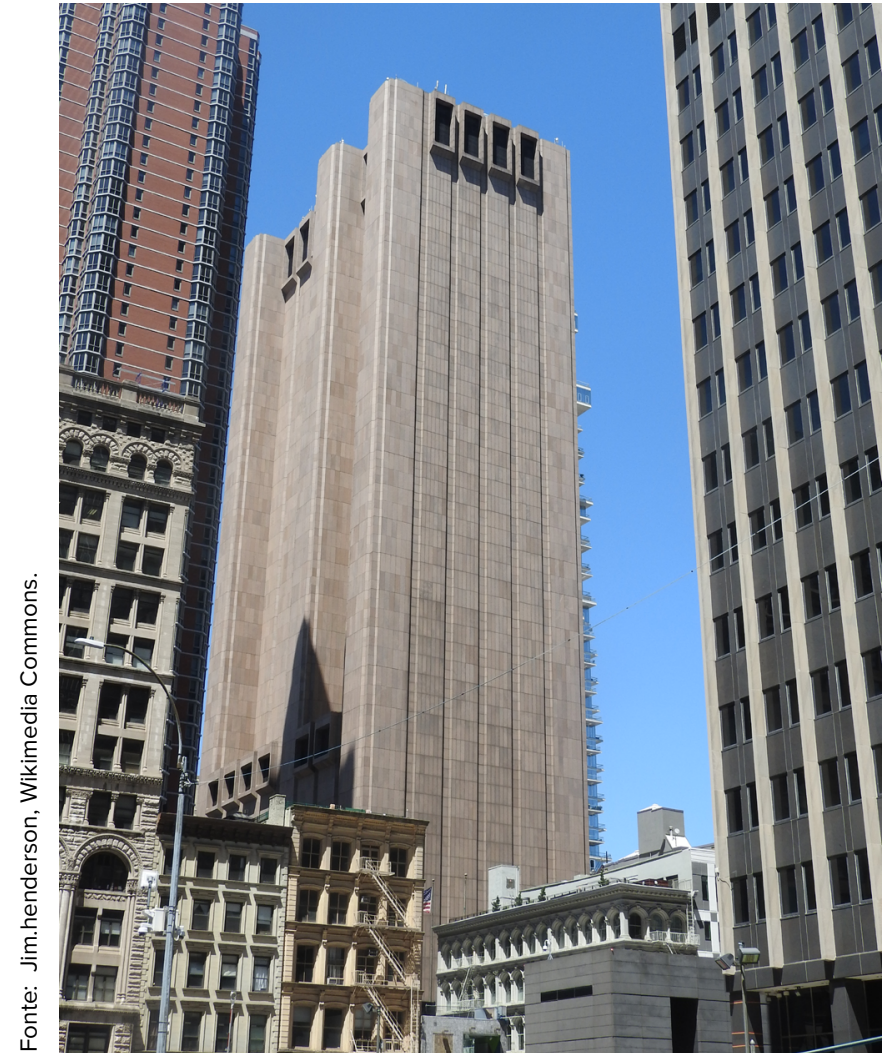

Figura 10. 33 Thomas Street, Nova Iorque, 2017.

dos impactos ambientais, sociais, urbanos e paisagísticos decorrentes da ampliação de uma infraestrutura global. De Data Centers a Cabos Submarinos, de infraestruturas urbanas à Internet das coisas, a fisicalidade da Internet desempenha um papel fundamental nas questões econômicas, sociotécnicas e ambientais dentro das geografias em que estão enraizadas, revelando-se como um proeminente articulador dos processos urbanos que estão remodelando a geopolítica planetária. Organizando em diversos territórios, interagindo com diversos agentes e revelando arquiteturas pouco interpretadas, a centralidade vital da infraestrutura em uma sociedade cada vez mais conectada reverbera desafios existentes, mas cada vez mais complexos, como processos de urbanização, acesso desigual e alto impacto ambiental.

Nesse sentido, os processos de digitalização da vida, intensificados durante a pandemia de COVID-19, se expandiram no trabalho, educação, economia e políticas públicas, nas quais a transposição de átomos para bytes se torna um subterfúgio para a continuidade. O que tornou ainda mais visível a desigualdade no acesso à Internet no Brasil, país que ocupa o quarto lugar (ROSER; RITCHIE; ORTIZ-OSPINA, 2015) no ranking de número absoluto de usuá- rios de Internet, mas que não conta com uma infraestrutura universal de telecomunicações. Exemplos recentes, como o programa federal de auxílio emergencial - no qual, no primeiro momento, era necessário acessar o aplicativo da Caixa Econômica Federal para realizar o cadastramento - , ou o acesso desigual a plataformas de pedagogia digital - para o qual muitos estudantes e escolas da rede pública não conseguiram se adaptar - descortinou desafios significativos para um país com cerca de 70 milhões de pessoas off-line (TIC CULTURA 2018, 2019) e outros 70 milhões sem acesso de alta velocidade ou qualidade. Assim, o debate sobre o acesso à Internet se estende junto com novos conceitos de cidadania. Se para exercer a cidadania precisamos estar conectados, o acesso à infraestrutura de Internet deve ser um direito fundamental.

De fato, o acesso à Internet está relacionado à forma como sua infraestrutura está distribuída pelo território. Assim, amplia-se a necessidade da análise urbana e arquitetônica dessa infraestrutura. A revelação dos Data Centers deve se juntar a pesquisas sobre backbones, cabos de fibras ópticas, antenas e transmissões por satélite, a partir da análise de suas especificidades e como esses componentes se relacionam com as geografias que estão inseridas. Assim, contribuir para territorializar essa desigualdade e estimular interpretações dos diversos processos de urbanização decorrentes da infraestrutura da Internet.

\section{Notas de fim:}

1. O presente artigo foi extraído de ZALIS, Michel. Entre Aparência e Performance: desdobramentos de uma arquitetura da Internet. Orientação: João Masao Kamita. Trabalho de Conclusão de Curso (Arquitetura e Urbanismo) - Departamento de Arquitetura e Urbanismo, Pontifícia Universidade Católica do Rio de Janeiro, Rio de Janeiro, jun. 2020.

2. GAFAM é o acrônimo para Google, Apple, Facebook, Amazon e Microsoft.

3. Banham começou a escrever o livro Making Architecture: the paradox of high tech, sobre a arquitetura High Tech, em 1987, seguindo a sugestão de seu editor Axel Menges. Após sua morte, em 1988, haviam apenas manuscritos da suposta introdução, que foram compilados e publicados como High Tech and Advanced Engineering (GANNON, 2017, p. 233).

4. Do inglês, "centro de dados".

5. Dados de abril de 2020 da quantidade de usuários de Internet no mundo (DATA REPORTAL, 2020).

6. "Galpão não decorado" é uma expressão cunhada pela prof. Ana

Revista online do Departamento de Arquitetura e Urbanismo da Pontifícia Universidade Católica do Rio de Janeiro - PUC-Rio, Brasil Ano 8 - No으 9 - ISSN 2446-7340 
Luiza Nobre para caracterizar os Data Centers. Diferentemente dos galpões decorados de Las Vegas (VENTURI; SCOTT BROWN; IZENOUR, 1978, p.115), dificilmente existe uma placa ou ornamento para simbolizar e identificar essa arquitetura hipertecnológica.

7. Liam Young, na abertura da edição especial da Architectural Design, Machine Landscapes, afirma que apenas um engenheiro de Data Center do Facebook é capaz de monitorar 25 mil servidores (YOUNG, 2019, p. 8).

8. Após ter sido recusada uma visita a um Data Center solicitada ao Google, Gerrard contratou um fotógrafo e um helicóptero para retratar o edifício. O trabalho se utiliza das fotografias para pesquisar e usar como molde para renderizar vídeos e imagens hiper-realísticos do Data Center do Google em Oklahoma. A simulação foi feita com os mesmos softwares para modelar videogames, abordando o tema da computação através da computação em si.

9. Ex-analista de sistema da Agência Central de Inteligência (CIA) e da Agência Nacional de Segurança (NSA) que tornou público, em 2013, documentos sigilosos que revelaram um sistema de vigilância global operado pelo Governo dos Estados Unidos.

\section{Referências Bibliográficas:}

ALGER, Douglas. The art of data center: A look inside. Nova Jersey: Prentice Hall, 2013.

ANDRAE, Anders S. G.; EDLER, Tomas. On global electricity usage of communication technology: Trends to 2030. Challenges, v. 6, n. 1, p. 117-157, 2015.

BANHAM, Reyner. The architecture of well-tempered environment. 2nd ed. Chicago: University of Chicago Press, 1984.

. High Tech and Advanced Engineering. In: GANNON, Todd. Reyner Banham and the Paradoxes of High Tech. Los Angeles: Getty Publications, 2017.

CISCO. Cisco anual internet report. 2018. Relatório. Disponível em: cisco.com/c/en/us/solutions/collateral/executive-perspectives /annual-internet-report/white-paper-c11-741490.pdf. Acesso em: 2, jul. 2020.

DATA REPORTAL. Digital around the world. 2020. Relatório. Disponível em: https://datareportal.com/global-digital-overview. Acesso em: 7, dez. 2020.

DIGUET, Cécile; LOPEZ, Fanny. The spatial and energy impact of data centers on the territories. Angers: ADEME Report, 2019.

DUCCOURTIEUX, Cecile. La France esquisse des pistes pour faire payer plus d'impôts aux géants du Web. Le Monde, dez. 2012. Disponível em: https://www.lemonde.fr/economie /article/2012/12/20/la-france-esquisse-des-pistes-pour-faire-payer -plus-d-impots-aux-geants-du-web_1808875_3234.html. Acesso em: 5 , mai. 2020

EISENMAN, Peter. Visões que se desdobram: A arquitetura na era da mídia eletrônica. (1992) In: NESBITT, Kate (Org.). Uma Nova Agenda para a Arquitetura: antologia teórica (1965-1995). Tradução: Vera Pereira. São Paulo: Cosac Naify, 2013, p. 600 - 607

FARD, Ali. Grounding the Cloud. Tese (Mestrado) - Universidade de
Harvard, Cambridge, 2018.

GALlAGER, Ryan; MOLTKE, Henrik. TITANPOINTE: The NSA's Spy Hub in New York, Hidden in plain sight. The Intercept, 2016. Disponível em: https://theintercept.com/2016/11/16/the-nsas-spy -hub-in-new-york-hidden-in-plain-sight/. Acesso em: 30, jun. 2020.

The wiretaps rooms: The NSA's Hidden Spy Hub in eight U.S. Cities. The Intercept, 2018. Disponível em: https://theintercept .com/2018/06/25/att-internet-nsa-spy-hubs/. Acesso em: 30, jun. 2020 .

GANNON, Todd. Reyner Banham and the Paradoxes of High Tech. Los Angeles: Getty Publication, 2017.

GLANZ, James. Power, pollution and the Internet. New York Times, 22, set. 2012. Disponível em: https://www.nytimes.com/2012/o9/23 /technology/data-centers-waste-vast-amounts-of-energy-belyingindustry-image.html. Acesso em: 20, mai. 2020.

GRAHAM, Stephen. Data Archipelagos. In: MAY, Kyle (Ed.). Data Space. Nova Iorque: CLOG, 2012, p. 20-22.

GREENPEACE. Clicking Clean: Who is winning the race to build a green internet?. Washington, 2017.

HOLT, Jennifer; VONDERAU, Patrick. "Where the internet lives" Data Center and Cloud Infrastructure. In: PARKS, Lisa; STAROSIELSKI, Nicole (Ed.). Signal Traffic: critical studies of media infrastructures. Chicago: Board of Trustees of the University of Illinois, 2015.

JOHN GERRARD. Works. Site do artista. Disponível em: http://www johngerrard.net/farm-pryor-creek-oklahoma-2015.html. Acesso em: 20, mai. 2020.

KAHN, Louis. Forma e Design. São Paulo: Martins Fontes, 2010.

KOOLHAAS, Rem. Museum in the Countryside: Aesthetic of the Data Center.ArchitecturalDesign. Número especial: Machine Landscapes: Architectures of the post Anthropocene, Nova Jersey, v. 89, n. 1, p. 6o-65, jan./fev. 2019.

. Nova York Delirante. São Paulo: Cosac Naify. 2008.

METREVELI, Irakli. Georgian pensioner devastated after 'cutting Internet'. The Sydney Morning Herald, 9, abr. de 2011. Disponível em:https://www.smh.com.au/technology/georgian-pensioner -devastated-after-cutting-internet-20110409-1d837.html. Acesso em: 20, mai. 2020.

REINSEL, David; GANTZ, John; RYDNING, John. DataAge 2025, The Digitalization of the World: From Edge to Core. Massachusetts: IDC, 2018. Disponível em: https:/www.seagate.com/files/www-content /our-story/trends/files/idc-seagate-dataage-whitepaper.pdf. Acesso em: 20, mai. 2020.

ROSER, Max; RITCHIE, Hannah; ORTIZ-OSPINA, Esteban. Internet. OurWorldInData, 2015. Disponível em: https://ourworldindata.org /internet. Acesso em: 5, dez. 2020.

TIC CULTURA 2018: Pesquisa sobre o uso das tecnologias da informação e comunicação nos equipamentos culturais brasileiros = ICT in culture 2018: survey on the use of information and communication technologies in Brazilian cultural facilities. Relatório bilíngue. São Paulo: Comitê Gestor da Internet no Brasil, 2019. Disponível em: https://cetic.br/media/docs/publicacoes/1 /tic_cultura_2018_livro_eletronico.pdf. Acesso em: 30, nov. 2021. 
VENTURI, Robert; SCOTT BROWN, Denise; IZENOUR, Steven. Aprendiendo de Las Vegas: El simbolismo olvidado de la forma arquitectónica. Barcelona: Gustavo Gili, 1978.

WISNIK, Guilherme. Dentro do Nevoeiro. São Paulo: Ubu, 2018.

YOUNG, Liam. Neo-machine: Architecture without people. Architectural Design. Número especial: Machine Landscapes: Architectures of the post Anthropocene, Nova Jersey, v. 89, n. 1, p. 6-13, jan./fev. 2019. 